\title{
The Differences in Job Characteristics, Job Satisfaction, and Organizational Commitment of Taiwanese Expatriates Working in Mainland China
}

\author{
Sheng Wen Liu \\ Assistant Professor, Department of Marketing Management, Trasworld Institute of Technology \\ 1221, Jen-Nang Rd., Chia-Tong Li, Douliou, Yunlin, Taiwan R.O.C. \\ E-mail: swen@tit.edu.tw \\ Ralph Norcio (Corresponding author) \\ Professor and Associate Dean, College of Business and Management, Lynn University \\ 3601 N. Military Trail, Boca Raton, FL 33431, USA \\ Tel: 561-237-7010Ｅ-mail: rnorcio@lynn.edu \\ Jung Tsung Tu \\ Assistant Professor, Department of Business Administration, Chungyu Institute of Technology \\ 40, Yi 7th Rd., Keelung, Taiwan 201, R.O.C. \\ E-mail:suntu@cit.edu.tw
}

\begin{abstract}
With a population of 1.2 billion, mainland China has become a major target country for many foreign companies looking to expand their businesses because of its inexpensive labor and large market. In 2009, there were 77,642 companies from Taiwan operating in mainland China with fiscal expenditures exceeding US $\$ 47.77$ billion dollars. If Taiwan's foreign direct investment (FDI) and offshore investment expenditures were included, Taiwan would have had the second largest FDI in mainland China. The purpose of this study is to investigate the difference in job characteristics, job satisfaction, and organizational commitment depending on family location of Taiwanese expatriates working in mainland China. The entire accessible population of 6,156 Taiwanese expatriates was invited to participate by e-mail resulting in a valid sample of 389 responses. The methods of data analysis used in this study consisted of exploratory data analysis (EDA), exploratory factor analysis (EFA), internal consistency reliability, and two-tailed independent $t$-tests. Findings indicated that variety and autonomy, intrinsic job satisfaction, affective commitment, and normative commitment were identified as having positive significant differences between Taiwanese expatriates who were living with family in China and those not living with family in China. Further study to replicate the research in different countries in order to explore the relationships among job characteristics, job satisfaction, and organizational commitment of expatriates was recommended.
\end{abstract}

Keywords: Organizational commitment, Job characteristics, Job satisfaction, Expatriates, Mainland China, Family location

\section{Introduction and Background}

Before 1991, there were only 3,884 Taiwanese companies with fiscal expenditures exceeding US \$0.86 billion. However, more Taiwanese manufacturers are expanding to mainland China for less expensive labor. In 2009, there were 77,642 companies from Taiwan operating in mainland China with fiscal expenditures exceeding US \$47.77 billion (Ministry of Commerce of the People's Republic of China, 2009). Moreover, Taiwanese companies provide the seventh largest foreign direct investment (FDI) in mainland China. Hong Kong ranks first, followed by the United Kingdom, Japan, Korea, Germany, and the United States. If Taiwan's FDI offshore investment expenditures were included, Taiwan would have the second largest FDI in mainland China (Department of Investment Services Ministry of Economic Affairs, 2009). Based on this, it is important for Taiwanese human resource management scholars to 
undertake a study to not only determine the factors, which may cause expatriate employees to be willing to live and work in mainland China, but also to have a staff that identifies closely with, and supports the organization. Therefore, the purpose of this comparative (exploratory) study was to investigate the difference among job characteristics, job satisfaction, and organizational commitment of Taiwanese expatriates working in mainland China depending on family location.

\subsection{Expatriate Employees}

Expatriates are international assignees and employees who are sent by a firm from the home country to work in a foreign location. Most expatriate employees are managerial employees who go to work abroad and are assigned significant responsibilities. With the growth in the globalization of business, expatriate employees are becoming very important and their numbers are expected to continue to increase. Hence, expatriate employees have an important role as representatives of the home office and as bearers of organizational culture (Ali, Krishnan, \& Azim, 1997; Guzzo, 1996).

Expatriate failures, such as lost business or suppliers, the potential damage to customers, and the negative effects on staff members and employees in the local market (Frank E. Allen \& Associates, n.d.), could be costly to both the corporation involved and the individual expatriate. Consequences include financial failures, caused by increased direct costs, indirect costs, replacement costs, reduced productivity, or unstable corporate image, and lost sales (Ashamalla, 1998).

\subsection{Meyer and Allen's Three-Component Model of Organizational Commitment}

Meyer and Allen (1984) conducted two studies with two-group samples of 64 introductory psychology students and 130 employees from several administrative departments of a large university and additionally testing the side-bet theory. From their research findings, they proposed a model of organizational commitment (Meyer, \& Allen, 1991). Furthermore, Powell and Meyer (2004) conducted a study to test Becker's (1960) side-bet conceptualization of commitment within the context of Meyer and Allen's (1991) three-component model of organizational commitment. Their findings provided strong support for Becker's theory. The three-component model of organizational commitment reflected a psychological state of employees as the basis for maintaining employment in an organization, that includes a desire (affective commitment), an obligation (normative commitment), and a need (continuance commitment).

Affective commitment is a feeling of attachment and belonging to an organization, that includes the structure of the organization, the type of work experiences, and personal characteristics (Hartmann \& Bambacas, 2000). Affective commitment links employees' emotional involvement and identification with attachment to the organization (Tan \& Akhtar, 1998).

Normative commitment is the obligation an employee feels for remaining with the organization (Tan \& Akhtar, 1998). Normative commitment could increase by receiving such benefits as advance payment for continuing education, and consideration of special needs and training (Hartmann \& Bambacas, 2000).

Continuance commitment refers to the awareness of the consequences associated with leaving an organization, or the awareness of a lack of alternatives. Employees choose to remain in an organization based on continuance commitment because they need to do so (Meyer \& Allen, 1991). Lost benefits include accrued pensions, promotions based on tenure, loss of values, future opportunities, or lost efforts if skills or systems are not transferable (Hartmann \& Bambacas, 2000).

\subsection{Job Satisfaction}

Job satisfaction has been conceptualized in many ways. It is not a unidimensional concept, and is of wide interest to people employed in organizations, and also to those who study organizations (Zangaro \& Soeken, 2005). One of the popular conceptualizations is proposed by Locke (1976), the intrinsic, extrinsic, and general job satisfaction model that is based on Herzberg's motivation-hygiene theory (Locke, 1976; Namann, 1993b). Intrinsic job satisfaction is obtained from performing the work and experiencing feelings of accomplishment, self-actualization, and identity with the job. Extrinsic job satisfaction is obtained from the reward bestowed on an individual by superiors, colleagues or the organization, and can take the form of compensation, recognition, or advancement. General satisfaction is an aggregate of satisfaction with various job activities or a combination of several measures of overall satisfaction. No prominent conceptualizations of job satisfaction have been found in the literature, but the use of the intrinsic, extrinsic, and general distinction seems to be the most appropriate concept for international research (Naumann, 1993a; Naumann, 1993b; Zangaro \& Soeken, 2005).

\subsection{Job Characteristics}

Job characteristics have been tested in many studies and have shown a positive influence on expatriates' success (Bhuian \& Menguc, 2002; Morley \& Flynn, 2004; Naumann, 1993a; Bhuian, Al-Shammari, \& Jerfri, 2001; Nauman, Widmier, \& Jackson, Jr., 2000). The Job Characteristics Inventory (JCI) developed by Sims, Szilagyi, and Keller (1976) 
was an extension of the job characteristics scales that were developed by Hackman and Lawler (1971). The six dimensions included in the JCI were segregated into two categories: 1) variety, autonomy, task identity, and feedback (refer to job satisfaction), and 2) dealing with others and friendship opportunities (not related to job satisfaction, but were included to determine the impact of the interpersonal characteristics of job design). In order to demonstrate reliability, construct validity, discriminant validity and convergent validity of the JCI, Sims, Szilagyi, and Keller (1976) tested two highly divergent samples: 1,161 medical center personnel and 192 supervisors and managers from a southwestern U.S. manufacturing firm with approximate sales of \$120 million as reported in 1973.

\section{Research Question}

Are there significant differences in job characteristics, job satisfaction, and organizational commitment depending on family location of Taiwanese expatriates working in mainland China?

\section{Research Methodology}

\subsection{Research Design}

A quantitative, comparative (exploratory) online survey research design was used to explain the relationships among job characteristics, job satisfaction, and organizational commitment according to family location. The data was collected by an online survey from Taiwanese expatriates working in mainland China.

A self-report survey consisting of three parts was used in this study. The first three questions in Part 1 (Job Characteristics) are filter questions, developed by the researcher to identify a participant's qualifications (at least 18 years old, and not an owner or a significant shareholder who had decision making responsibility for the company), and family location (Family is living with you in China, Family is not living with you in China). Part 1 is Job Characteristics, uses the Job Characteristics Inventory (JCI) as developed by Sims, Szilagyi, and Keller (1976), which includes six dimensions: variety, autonomy, feedback, task identity, dealing with others, and friendship opportunities. Part 2, Job Satisfaction, uses the Minnesota Satisfaction Questionnaire (MSQ) as developed by Weiss et al. (1967), which includes three dimensions: intrinsic job satisfaction, extrinsic job satisfaction, and general job satisfaction. Part 3, Organizational Commitment, uses the Three-Component Model (TCM) Employee Survey as developed by Meyer and Allen (1991; 1997), which includes three dimensions: affective commitment, normative commitment, and continuance commitment.

In order to answer the research question and describe all variables, frequency distributions, measures of central tendency, and variability tests were performed. To determine whether there were significant differences in job characteristics, job satisfaction, and organizational commitment depending on family location of Taiwanese expatriates working in mainland China, two-tailed $t$-tests were utilized.

\section{Data Analyses and Results}

\subsection{Exploratory Factor Analysis}

Exploratory factor analysis (EFA) is a technique to help an investigator to understand the relationships among variables, represent the validity of constructs, extract common factors, and reproduce or explain the correlation matrix by examining the correlation of large sets of items among interval-level variables (Leech et al., 2005). Three instruments (job characteristics, job satisfaction, and organizational commitment) used in this study were reproduced from previous studies. Their construct validity had already been established by their developers and other researchers in different studies. However, to establish construct validity in this study, EFA was conducted to contrast with previous studies and further validate the instrument and examine the underlying structure for the total items of each variable.

The original job characteristics instrument included six dimensions, variety (5 items), autonomy ( 7 items), friendship opportunity (6 items), feedback (4 items), task identity (4 items), and dealing with others (4 items). Job satisfaction included three dimensions, intrinsic job satisfaction (12 items), extrinsic job satisfaction (6 items) and general satisfaction (20 items). Organizational commitment included three dimensions, affective commitment, normative commitment, and continuance commitment with each dimension having six items. To examine the underling structure for these variables, principal axis factor analysis with varimax rotation was executed.

Before employing EFA, the Kaiser-Meyer-Olkin (KMO) test and Bartlett's test were conducted. KMO was conducted to determine if there were enough items to predict for each factor. The KMO value of each variable, job characteristics, job satisfaction (intrinsic and extrinsic), general job satisfaction, and organization commitment was greater than .70, which means there were sufficient items for each factor. In addition, the Bartlett value has to be significant $(p<.05)$ in order for EFA to be used. In this study, the significance value for each variable was .000 , which means the variables correlated highly enough to give logical support for factor analysis (Leech et al., 2005).

After the KMO and Bartlett tests were conducted, principal axis factor analysis with varimax rotation was executed for each variable. For job characteristics, based on the scree plot test and using an eigenvalue greater than one, after rotation, five factors were extracted with $59.12 \%$ of the variance accounted for by the five factors. This result was 
different from the original instrument which contained six factors. According to the results of the new factor loading for job characteristics (JC), the new five factors were renamed. The eigenvalues for these five factors (variety and autonomy, friendship opportunity, feedback, task identity, and dealing with others) were $9.726,19.673 \%$ of the variance; $2.986,13.791 \%$ of the variance; $2.149,12.324 \%$ of the variance; $1.608,7.398 \%$ of the variance; and $1.268,5.983 \%$ of the variance, respectively. On the other hand, all items and factor loadings for the rotated factors were greater than .40, which means that each item has absolute value (Leech et al., 2005).

\subsection{Reliability Analysis}

To assess the reliability of the instrument in a study, Cronbach's coefficient alpha is the most commonly used method to compute the internal consistency reliability (Leech et al., 2005). In this study, Cronbach's alpha was used to assess consistency of three constructs and their sub-constructs. Job characteristics had five sub-constructs (variety and autonomy, friendship opportunity, feedback, task identity, and dealing with others), job satisfaction had three-constructs (intrinsic, extrinsic, and general satisfaction), and organizational commitment had three sub-constructs (affective, normative, and continuance commitment).

As shown in Table 1, the coefficients of all the variables were greater than .70 (ranging from .734 to .934) which indicates the item construct scale for each variable has rational consistency reliability.

\subsection{The Mean and Standard Deviations of All Variables}

Of the 389 participants, 94 (24.2\%) subjects were living with their family in China, and 295 (75.8\%) were living in China without their family. Table 2 shows the summary of means, standard deviations, skewness and kurtosis of all variables. Organizational commitment was calculated by 18 items used to measure three constructs, affective commitment, normative commitment, and continuance commitment. Job satisfaction was calculated by 20 items which included 18 items used to measure two constructs, intrinsic job satisfaction and extrinsic job satisfaction. Job characteristics were calculated by 30 items used to measure five constructs, variety and autonomy, friendship opportunity, feedback, dealing with others, and task identity. As shown in Table 2, the skewness of all variables was more than -1.0 . Once the skewness is less than -1.0 or more than 1.0, it means the frequency distribution for all variables was nearly normal (Leech et al., 2005).

\subsection{Two-Tailed Independent t-Test-Family Location}

In order to identify whether there were significant differences in job characteristics, job satisfaction and organizational commitment depending on family location, a two-tailed independent $t$-test was conducted. An independent $t$-test was utilized to examine each variable's two group means to determine if they were significantly different from each other (Leech, et al., 2005). For family location, equality of variances between yes (they are living with family in China) and no (they are not living with family in China) must be identified before adopting a two-tailed $t$-test to assess if there were significant difference in job characteristics, job satisfaction, and organizational commitment with their sub-constructs depending on family location. To examine the equality of variances for these variables across two or more groups, Levene's test was utilized.

As shown in Table 3, Levene's test found equality of variances across the Taiwanese expatriates living with family in China and those that are not living with family in China samples in variety and autonomy, friendship opportunity, task identity, dealing with others, general job characteristics, extrinsic job satisfaction, affective commitment, normative commitment, and continuance commitment. On the other hand, intrinsic job satisfaction, affective commitment, and continuance commitment displayed unequal variables across samples. A two-tailed independent $t$-test was also utilized to examine whether there were significant difference in job characteristics, job satisfaction, and organizational commitment with their sub-constructs. As shown in Table 3, the results of two-tailed independent $t$-test found that variety and autonomy $(t=3.040, p=.003)$, intrinsic job satisfaction $(t=3.174, p=.002)$, affective commitment $(t=$ 2.554, $p=.012)$, and normative commitment $(t=3.216, p=.001)$ were identified as having positive significant differences between two groups of Taiwanese expatriates who were living with family in China and those not living with family in China. Based on the results provided in Tables 3, the research question was answered.

\section{Discussion}

\subsection{Descriptive and Comparative Analysis of Family Location, Job Characteristics, Job Satisfaction, and Organizational Commitment of Sample}

Based on the data collection of 389 valid responses 94 (24.2\%) subjects were living with family in China, and 295 (75.8\%) were living in China without family. Based on the analysis of the means and standard deviations of all variables in organizational commitment, affective commitment (4.40) was the highest rated dimension, followed by normative commitment (4.28), and continuance commitment (3.86). The mean for general organizational commitment was 4.01. For job satisfaction, the means were general job satisfaction 3.54, intrinsic job satisfaction 3.63, and extrinsic job satisfaction 3.39. For job characteristics, the mean of general job characteristics was 3.62. The highest rating of the 
five dimensions of job characteristics was variety and autonomy (3.80), followed by friendship opportunity (3.73), dealing with others (3.57), feedback (3.41), and task identity (3.29). The research question examined the difference in job characteristics, job satisfaction, and organizational commitment depending on family location of Taiwanese expatriates working in mainland China. Through an independent two-tailed t-test, the results found there were significant differences in the perception of job characteristics, job satisfaction, and organizational commitment according to family location. Moreover, family location not only had a strong correlation with normative commitment using the Pearson correlation analysis, but also was a positive significant explanatory variable of normative commitment.

\section{Recommendations for Future Study}

To further explore the relationships among job characteristics, job satisfaction, and organizational commitment, future study should be based on the interpretations and conclusions in this study. In addition, further study should explore the impact of job characteristics on job satisfaction and organizational commitment in order to obtain an in-depth understanding of their relationships. This study provided overall research to determine the difference in job characteristics, job satisfaction, and organizational commitment of Taiwanese expatriates working in mainland China depending on family location. Further studies should undertake an in-depth examination of the relationships with different target populations based on the findings of this study in order to gain better understandings about their relationships. Finally, observations or interviews combined with surveys should be considered for future studies to examine the relationships among job characteristics, job satisfaction, and organizational commitment.

\section{References}

Ali, A. J., Krishnan, K., \& Azim, A. (1997). Expatriate and indigenous managers' work loyalty and attitude toward risk. The Journal of Psychology, 131, 260-270.

Ashamalla, M. H. (1998). International human resource management practices: The challenge of expatriation. Competitiveness Review, 8, 54-65.

Becker, H.S. (1960). Notes on the concept of commitment. American Journal of Sociology, 66, 32-40.

Bhuian, S. N., Al-Shammari, E. S., \& Jefri, O. A. (2001). Work-related attitudes and job characteristics of expatriates in Saudi Arabia. Thunderbird International Business Review, 43, 21-31.

Bhuian, S. N., \& Menguc, B. (2002). An extension and evaluation of job characteristics, organizational commitment and job satisfaction in an expatriate, guest worker, sales setting. The Journal of Personal Selling \& Sales Management, 22. 1-11.

Department of Investment Services Ministry of Economic Affairs. (2009). The Situation of Taiwanese Corporation in China. [Online] Available: http://twbusiness.nat.gov.tw/analy/a02-5.htm (Retrieved from January 20, 2009)

Frank E. Allen \& Associates. (n.d.). Too many, too much cost, too little planning. [Online]Available: http://www.frankallen.com/Executive_Reports/Expatriate/Expatriate_Failures/expatriate_failures.html (Retrieved from June 1, 2006)

Guzzo, R. A. (1996). The expatriate employee. Journal of Organizational Behavior, 123-137.

Hackman, J. R., \& Lawler, E. E. (1971). Employee reactions to job characteristics. Journal of Applied Psychology Monographs, 55, 259-286.

Hartmann, L. C., \& Bambacas, M. (2000). Organizational commitment: A multi method scale analysis and test of effects. International Journal of Organization Analysis, 8, 89-108.

Leech, N. L., Barrett, K. C., \& Morgan, G. A. (2005). SPSS for intermediate statistics use and interpretation. Mahwah, NJ: Lawrence Erlbaum.

Locke, E. A. (1976). The nature and consequences of job satisfaction. In M.D.

Meyer, J. P., \& Allen, N. J. (1984). Testing the "side-bet theory" of organizational commitment: Some methodological considerations. Journal of Applied Psychology, 69. 372-378.

Meyer, J. P., \& Allen, N. J. (1991). A three-component conceptualization of organizational commitment. Human Resource Management Review, 1. 61-89.

Meyer, J. P., \& Allen, N. J. (1997). Commitment in the Workplace: Theory, Research, and application. Thousand Oaks, CA: Sage Publications.

Ministry of Commerce of the People's Republic of China (2009). China's overseas direct investment statistics 2009. [Online] Available: http://www.mofcom.gov.cn/static/v/tongjiziliao/v.html/1(Retrieved from January 20, 2009). 
Morley, M. J., \& Flynn, M. (2004). The relationship between work-role characteristics and intercultural transitional adjustment domain patterns among a sample of US and Canadian expatriates on assignment in Ireland. Cross Cultural Management, 10, 42-57.

Naumann, E. (1993a). Antecedents and consequences of satisfaction and commitment among expatriate managers. Group \& Organizational Studies, 18, 153-187.

Naumann, E. (1993b). Organizational predictors of expatriate job satisfaction. Journal of International Business Studies, 24, 61-80.

Naumann, E., Widmier, S. M., \& Jackson, Jr, D. W. (2000). Examining the relationship between work attitudes and propensity to leave among expatriate salespeople. The Journal of Personal Selling \& Sales Management, 20, $227-241$.

Powell, D. M., \& Meyer J. P. (2004). Side-bet theory and the three-component model of organizational commitment. Journal of Vocational Behavior, 65, 157-168.

Sims, H. P., Szilagyi, A. D., \& Keller, R. T. (1976). The measurement of job characteristics. Academy of Management Journal, 19, 195-212.

Tan, D. S. K., \& Akhtar, S. (1998). Organizational commitment and experienced burnout: An exploratory study from a Chinese cultural perspective. International Journal of Organizational Analysis, 6, 310-333.

Weiss, D. J., Dawis, R. V., England, G. W., \& Lofquist, L. H. (1967). Manual for the Minnesota satisfaction questionnaire. Minnesota Studies in Vocational Rehabilitation, 22. Mineapolis: Industrial Relations Center, University of Minnesota.

Zangaro, G. A., \& Soeken, K. L. (2005). Meta-analysis of the reliability and validity of part of the index of work satisfaction across studies. Journal of Nursing Measurement, 13, 7-22.

Table 1. Reliability Statistics

\begin{tabular}{ccc}
\hline Variable & Item & Cronbach's Alpha $(\alpha)$ \\
\hline Variety and autonomy & 10 & .885 \\
Friendship opportunity & 7 & .872 \\
Feedback & 7 & .822 \\
Task identity & 3 & .791 \\
Dealing with others & 3 & .734 \\
General job characteristics & 30 & .911 \\
Intrinsic job satisfaction & 9 & .891 \\
Extrinsic job satisfaction & 9 & .881 \\
General satisfaction & 20 & .934 \\
Affective commitment & 4 & .894 \\
Normative commitment & 9 & .893 \\
Continuance commitment & 5 & .812 \\
General organizational commitment & 18 & .742 \\
\hline
\end{tabular}


Table 2. Descriptive Analysis of All Variables

\begin{tabular}{cccc}
\hline Variable (Number of Items) & Mean & Std.deviation & Skewness \\
\hline Organizational commitment (18) & 4.0081 & .63443 & -.005 \\
Affective commitment (4) & 4.4044 & 1.29020 & -.165 \\
Normative commitment (9) & 4.2751 & 1.05293 & -.146 \\
Continuance commitment (5) & 3.8576 & 1.15624 & .027 \\
Job satisfaction (20) & 3.54 & .57608 & -.810 \\
Intrinsic job satisfaction (9) & 3.6347 & .60789 & -.892 \\
Extrinsic job satisfaction (9) & 3.3867 & .64437 & -.792 \\
Job characteristics (30) & 3.6170 & .45076 & -.239 \\
Variety and autonomy (10) & 3.7956 & .53188 & -.193 \\
Friendship opportunity (7) & 3.733 & .64999 & -.489 \\
Feedback (7) & 3.4065 & .6312 & -.259 \\
Dealing with others (3) & 3.5733 & .52499 & -.091 \\
Task identity (3) & 3.2853 & .71715 & -.061
\end{tabular}

Table 3. Two-tailed Independent t-Test of Job Characteristics, Job Satisfaction, and Organizational Commitment According to Family Location

\begin{tabular}{ccccc}
\hline Variable/Family Location & \multicolumn{2}{c}{$\begin{array}{c}\text { Levene's test for equality of } \\
\text { variances }\end{array}$} & $t$-test for equality of means \\
\cline { 2 - 5 } & $F$ & Sig. $(p)$ & $T$ & Sig. $(p)$ \\
\hline Variety and autonomy & .013 & .910 & 3.040 & .003 \\
Friendship opportunity & 4.044 & .045 & $1.328^{\mathrm{a}}$ & .184 \\
Feedback & .498 & .481 & -.013 & .989 \\
Task identity & .177 & .675 & -1.848 & .065 \\
Dealing with others & .161 & .689 & 1.684 & .093 \\
General job characteristics & .684 & .409 & 1.519 & .130 \\
Intrinsic job satisfaction & 8.648 & .003 & $3.174^{\mathrm{a}}$ & .002 \\
Extrinsic job satisfaction & .000 & .999 & .874 & .383 \\
General satisfaction & 2.201 & .139 & 1.875 & .061 \\
Affective commitment & 5.025 & .026 & $2.554^{\mathrm{a}}$ & .012 \\
Normative commitment & .369 & .545 & 3.216 & .001 \\
Continuance commitment & 8.208 & .004 & $-.001^{\mathrm{a}}$ & .999 \\
General organizational & .364 & .547 & 1.383 & .167
\end{tabular}

Note 1. a - Adjusted t-test formula for unequal variances 